\title{
Association of Whole Blood Viscosity With Metabolic Syndrome in Type 2 Diabetic Patients: Independent Association With Post-Breakfast Triglyceridemia
}

\author{
Satomi Minato ${ }^{\mathrm{a}, \mathrm{b}}$, Akiko Takenouchic ${ }^{\mathrm{c}}$, Junko Uchida ${ }^{\mathrm{d}}$, Ayaka Tsuboi ${ }^{\mathrm{a}, \mathrm{e}}$, Miki Kurata ${ }^{\mathrm{a}, \mathrm{c}, \mathrm{d}}$, \\ Keisuke Fukuo a, c, d, Tsutomu Kazumia, f, g
}

\begin{abstract}
Background: Associations of whole blood viscosity (WBV) with metabolic syndrome (MS) have not been extensively studied in patients with type 2 diabetes.

Methods: Intrapersonal means of 12 measurements of waist circumference, blood pressure (BP) and high-density lipoprotein cholesterol and those of six measurements of fasting and post-breakfast triglycerides (TG) during 12 months were calculated in a cohort of 168 patients with type 2 diabetes. Based on these means, MS was diagnosed according to the modified National Cholesterol Education Program Adult Treatment Panel III criteria with the Asian definition of abdominal obesity. WBV was calculated from hematocrit and total serum protein concentrations by a validated formula.
\end{abstract}

Results: Diabetes patients with MS $(\mathrm{n}=77)$ had higher WBV as compared to those without MS $(6.38 \pm 0.06$ vs. $6.10 \pm 0.07 \mathrm{cP}, \mathrm{P}=0.004)$. As the number of MS components increased, WBV increased (component number 1: $6.12 \pm 0.10,2: 6.09 \pm 0.10,3: 6.37 \pm 0.08,4: 6.42$ $\pm 0.10,5: 6.30 \pm 0.15 \mathrm{cP}$, P for trends $=0.001)$. Multiple regression analysis revealed that male gender, diastolic BP and post-breakfast TG were determinants of WBV independent of fasting TG, body mass index $(\mathrm{BMI})$ and waist circumference $\left(\mathrm{R}^{2}=0.258\right)$.

Conclusions: Both the presence of MS and the number of MS com-

Manuscript accepted for publication December 24, 2016

aResearch Institute for Nutrition Sciences, Mukogawa Women's University, Nishinomiya, Hyogo, Japan

${ }^{\mathrm{b}}$ Graduate School of Human Science and Environment, University of Hyogo, Himeji, Hyogo, Japan

cDepartment of Food Sciences and Nutrition, School of Human Environmental Sciences, Mukogawa Women's University, Nishinomiya, Hyogo, Japan

dPostgraduate School of Food Sciences and Nutrition, Mukogawa Women's University, Nishinomiya, Hyogo, Japan

eDepartment of Nutrition, Osaka City Juso Hospital, Osaka, Japan

fDiabetes Division, Department of Medicine, Kohnan Kakogawa Hospital, Kakogawa, Hyogo, Japan

'Corresponding Author: Tsutomu Kazumi, Research Institute for Nutrition Sciences, Mukogawa Women's University, 6-46, Ikebiraki-cho, Nishinomiya, Hyogo 663-8558, Japan. Email: kazumi@mukogawa-u.ac.jp

doi: https://doi.org/10.14740/jocmr2885w ponents were associated with higher WBV in patients with type 2 diabetes. Physicians need to perform a close follow-up of type 2 diabetes patients with MS on inhibitors of sodium-glucose co-transporters 2, which may increase stroke risk associated with an increase in hematocrit and therefore blood viscosity. Post-breakfast TG was an independent determinant of WBV. Elevated WBV may represent an important confounder of the relationship between MS, postprandial hyperlipidemia and elevated cardiovascular risk in this population.

Keywords: Blood viscosity; Hematocrit; Postprandial TG; Metabolic syndrome; Type 2 diabetes

\section{Introduction}

Type 2 diabetes mellitus causes excessive morbidity and premature cardiovascular (CV) mortality. Although studies have documented the benefits of optimal glycemic control on microvascular complications, the effect of tight glycemic control on macrovascular complications is unclear [1]. In the Action to Control Cardiovascular Risk in Diabetes study, tight glycemic control increased CV and all-cause mortality [2]. Glitazones and saxagliptin (a dipeptidyl peptidase 4 inhibitor) increase the risk of hospitalization for heart failure [3, 4]. In the Empagliflozin, Cardiovascular Outcomes, and Mortality in Type 2 Diabetes study [5], empagliflozin, an inhibitor of sodium-glucose co-transporters 2 (SGLT-2), was associated with remarkable reduction of $\mathrm{CV}$ morbidity and mortality and all-cause death. In contrast, stroke incidence was slightly increased, although the result did not reach statistical significance [5]. A large meta-analysis of SGLT-2 inhibitors effect on CV risk resulted in a significant increase of stroke risk with their use [6]. Possible explanations are an increase in hematocrit and therefore blood viscosity as secondary effects of this class of drugs [7].

Whole blood viscosity (WBV) is inversely related to flow of insulin and glucose to insulin-sensitive tissues [8] and might therefore lead to insulin resistance, metabolic syndrome (MS) or type 2 diabetes. WBV has been shown to be a risk factor for type 2 diabetes [9] and coronary heart disease [10]. The relationship between WBV and MS has been investigated in non-diabetic population [11-13]; however, there was, as far as we know, no report on this issue in diabetic patients despite 
Table 1. Anthropometric, Clinical and Biochemical Characteristics of 168 Patients With Type 2 Diabetes and Correlation Coefficients of Whole Blood Viscosity Before (Simple) and After (Partial) Adjustment for Sex

\begin{tabular}{|c|c|c|c|}
\hline \multirow{2}{*}{ Variables } & \multirow{2}{*}{$\begin{array}{l}\text { Mean } \pm \mathrm{SE} \\
\text { or } \mathbf{n}, \%\end{array}$} & \multicolumn{2}{|c|}{ WBV } \\
\hline & & Simple & Partial \\
\hline Male (n, \%) & $90(53.6)$ & $-0.447 * *$ & Adjusted \\
\hline Age (years) & $62.3 \pm 0.8$ & -0.101 & -0.002 \\
\hline BMI $\left(\mathrm{kg} / \mathrm{m}^{2}\right)$ & $24.2 \pm 0.3$ & 0.106 & $0.238 * *$ \\
\hline Waist circumference $(\mathrm{cm})$ & $86.9 \pm 0.8$ & 0.078 & $0.184^{* *}$ \\
\hline Duration of diabetes (years) & $9.9 \pm 0.6$ & 0.018 & 0.031 \\
\hline Smokers (n, \%) & $58(34.3)$ & $0.225 * *$ & -0.017 \\
\hline Whole blood viscosity (cP) & $5.95 \pm 0.04$ & 1.000 & 1.000 \\
\hline Fasting PG (mg/dL) & $125 \pm 2$ & 0.011 & -0.001 \\
\hline Post-breakfast PG (mg/dL) & $154 \pm 4$ & 0.025 & -0.077 \\
\hline HbAlc (\%) & $7.0 \pm 0.5$ & 0.046 & 0.055 \\
\hline Total cholesterol (mg/dL) & $188 \pm 2$ & -0.011 & 0.147 \\
\hline HDL cholesterol (mg/dL) & $56 \pm 1$ & $-0.189 *$ & -0.123 \\
\hline LDL cholesterol (mg/dL) & $111 \pm 2$ & -0.007 & 0.080 \\
\hline Fasting TG (mg/dL) & $115 \pm 4$ & $0.199 *$ & $0.225^{* *}$ \\
\hline Post-breakfast TG (mg/dL) & $145 \pm 5$ & $0.230 * *$ & $0.222 * *$ \\
\hline $\mathrm{ACR}(\mathrm{mg} / \mathrm{g})$ & $84 \pm 25$ & -0.031 & 0.018 \\
\hline $\log$ ACR & $1.30 \pm 0.05$ & 0.021 & 0.085 \\
\hline $\mathrm{eGFR}\left(\mathrm{mL} / \mathrm{min} / 1.73 \mathrm{~m}^{2}\right)$ & $75.8 \pm 1.3$ & 0.064 & -0.019 \\
\hline Uric acid (mg/dL) & $5.2 \pm 0.1$ & $0.21 * *$ & 0.084 \\
\hline Systolic BP (mm Hg) & $128 \pm 1$ & -0.004 & 0.051 \\
\hline Diastolic BP (mm Hg) & $72 \pm 1$ & $0.32 * *$ & $0.249 * *$ \\
\hline Serum protein $(\mathrm{g} / \mathrm{dL})$ & $7.2 \pm 0.03$ & $0.213 * *$ & $0.221 * *$ \\
\hline $\operatorname{AST}(\mathrm{U} / \mathrm{L})$ & $24.4 \pm 1$ & $0.188 *$ & 0.067 \\
\hline $\operatorname{ALT}(\mathrm{U} / \mathrm{L})$ & $24 \pm 1$ & $0.256^{* *}$ & 0.129 \\
\hline GGT (U/L) & $46 \pm 4$ & $0.167^{*}$ & 0.051 \\
\hline $\begin{array}{l}\text { White blood cells } \\
\left(\times 10^{3} / \mu \mathrm{L}\right)\end{array}$ & $5.8 \pm 0.1$ & $0.169^{*}$ & 0.145 \\
\hline Red blood cell $\left(\times 10^{6} / \mu \mathrm{L}\right)$ & $451 \pm 4$ & $0.775 * *$ & $0.691 * *$ \\
\hline Hemoglobin (g/dL) & $14.0 \pm 0.1$ & $0.764 * *$ & $0.864^{* *}$ \\
\hline Hematocrit (\%) & $42.3 \pm 0.3$ & $0.994^{* *}$ & $0.993^{* *}$ \\
\hline
\end{tabular}

WBV: whole blood viscosity; PG: plasma glucose; TG: triglycerides; ACR: albumin/creatinine ratio; eGFR: estimated glomerular filtration rate; AST: aspartate aminotransferase; ALT: alanine aminotransferase; GGT: gamma-glutamyl transferase; BP: blood pressure. ${ }^{*} \mathrm{P}<0.05$, ${ }^{* *} \mathrm{P}$ $<0.01$.

increased WBV in this population [12]. We, therefore, have evaluated the relationship between estimated WBV and MS in patients with type 2 diabetes. Among MS components, fasting hypertriglyceridemia has been reported to have stronger effect on hemorheological alterations [11]. As postprandial hypertriglyceridemia is common in type 2 diabetes patients and it is a component of MS $[14,15]$, we evaluated association between
WBV and post-breakfast triglyceridemia as well.

\section{Patients and Methods}

We studied 168 patients with type 2 diabetes, whose details have been reported elsewhere $[16,17]$. They had been regularly attending the clinic for more than 6 months prior to enrollment and had eight or more monthly visits with anthropometric and blood pressure (BP) measurements and blood samplings during the following 12 months after enrollment. We excluded patients with hepatitis B surface antigen or antibodies against hepatitis $\mathrm{C}$ virus. Patients who had aspartate aminotransferase (AST) and alanine aminotransferase (ALT) of $100 \mathrm{U} / \mathrm{L}$ or greater, serum creatinine $\geq 2.0 \mathrm{mg} / \mathrm{dL}$ and proteinuria in nephrotic range were also excluded. Study protocol was consistent with the Japanese Government's Ethical Guidelines Regarding Epidemiological Studies in accordance with the Declaration of Helsinki.

For each subject on each monthly visit, waist circumference, weight and BP were measured. BP was measured by nurses using a sphygmomanometer after patients sat and rested for at least $5 \mathrm{~min}$. Blood was withdrawn at $2 \mathrm{~h}$ after breakfast taken at home and after an overnight fasting every other month as previously reported in details $[16,17]$. Plasma glucose, serum creatinine, hepatic enzymes, uric acid and other blood tests were measured by standard methods using an autoanalyzer. $\mathrm{HbA} 1 \mathrm{C}$ values were determined by high performance liquid chromatography. Low-density lipoprotein (LDL) cholesterol was calculated using Friedewald's formula in blood samples taken after an overnight fasting. Complete blood cell count was analyzed using an automated blood cell counter.

Of 168 patients with type 2 diabetes, 153 patients (91\%) had 12 visits with blood samplings described above. In the remaining 15 patients, blood was obtained after an overnight fasting. In each patient, we calculated a mean of 12 measurements of body mass index (BMI), waist circumference, WBV estimated as described below, total and high-density lipoprotein (HDL) cholesterol, $\mathrm{HbAlc}$, uric acid, BP, serum protein, hepatic enzymes and hematocrit. Six measurements of fasting and post-breakfast glucose, LDL cholesterol, fasting and postbreakfast TG averaged in each patient as well. Those means are shown in Table 1 and were used for the diagnosis of MS.

MS was defined according to the modified criteria of the National Cholesterol Education Program Adult Treatment Panel III guidelines [18]. Abdominal obesity was defined as a waist circumference greater than $85 \mathrm{~cm}$ in men and greater than $90 \mathrm{~cm}$ in women, according to the Japan Society for the Study of Obesity criteria [19]. Elevated BP was defined as systolic/diastolic BPs of 130/85 mm Hg or greater and/or current use of antihypertensive medicine. Hypertriglyceridemia was defined as a serum fasting TG level of $150 \mathrm{mg} / \mathrm{dL}$ or greater and/or current use of fibrates. Low HDL cholesterol level was defined as less than $50 \mathrm{mg} / \mathrm{dL}$ in women and as less than 40 $\mathrm{mg} / \mathrm{dL}$ in men. MS was defined as the presence of three or more components [18]. Patients in the present study had at least one component as all patients had diabetes.

WBV at 208/s of shear stress was calculated by a previ- 

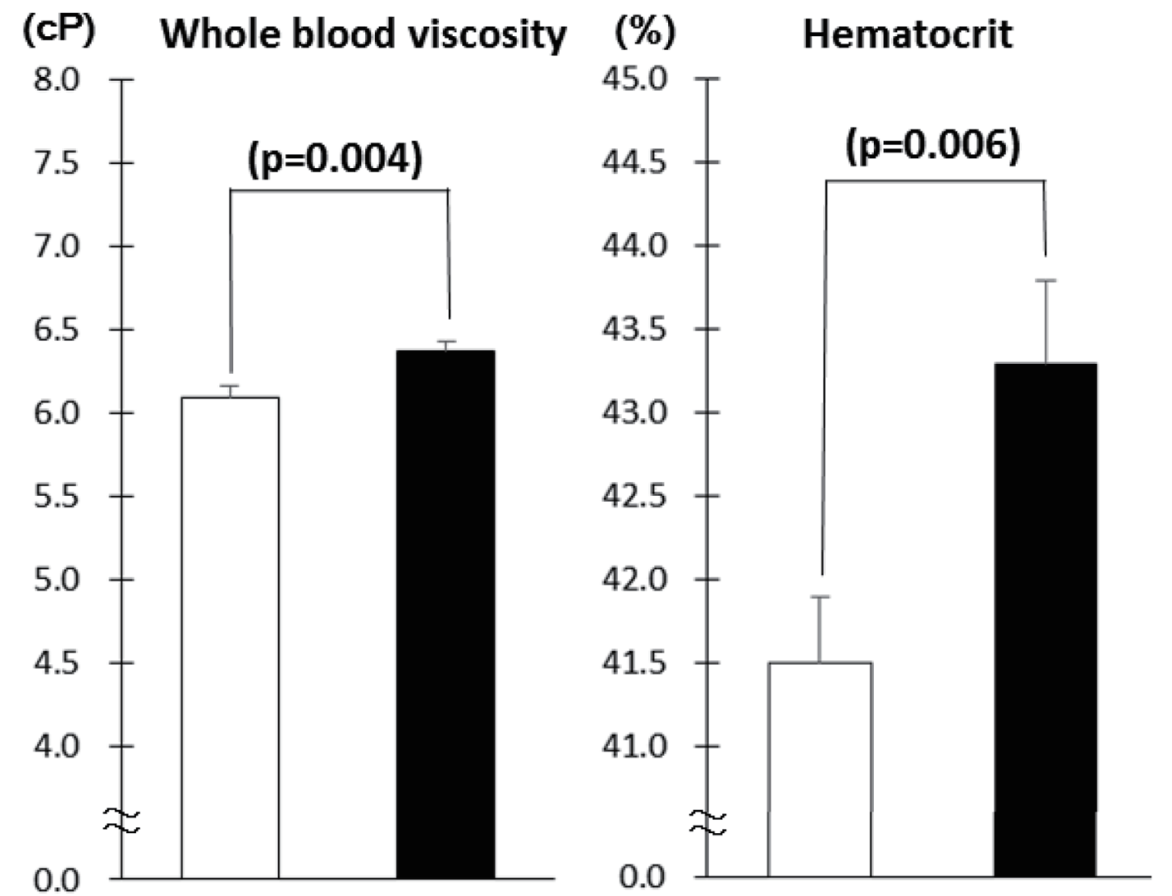

Figure 1. Whole blood viscosity and hematocrit in patients with type 2 diabetes as a function of the number of components of metabolic syndrome (mean \pm SE). The number of patients with component number from 1 to 5 is $33(19.6 \%), 58(34.5 \%), 42$ (25.0\%), $27(16.1 \%)$ and $8(4.8 \%)$, respectively. Associations of the number of MS components with WBV and hematocrit and P values for trend were derived using Jonckheere-Terpstra test.

ously validated formula [20] that takes into account hematocrit and serum proteins: WBV $(208 / \mathrm{s})=(0.12 \times \mathrm{h})+0.17 \times$ ( $\mathrm{p}-2.07)$, where $\mathrm{h}$ is hematocrit $(\%)$ and $\mathrm{p}$ is serum protein concentration $(\mathrm{g} / \mathrm{dL})$. Hematocrit and serum protein concentrations used were respective averages of 12 measurements over 12 months in each patient. The unit for viscosity is the centipoise (cP) corresponding to the ratio of the shear rate of blood to the shear rate of water.

Urinary albumin was measured once during the first 3 4 months after enrollment in random urine samples using a turbidimetric immunoassay and expressed as albumin/creatinine ratio (ACR). Serum and urinary creatinine were measured enzymatically and estimated glomerular filtration rate (eGFR) was determined using the equation recommended by the Japanese Society for Nephrology [21].

\section{Statistical analysis}

Data were presented as mean $\pm \mathrm{SE}$. Differences between two groups were analyzed by $t$-test and frequencies of conditions by Chi-square tests. Associations of the number of MS components with WBV and hematocrit and $\mathrm{P}$ values for trend were derived using Jonckheeree-Terpstra test. Correlations of WBV and hematocrit were evaluated by Pearson correlation analysis. Stepwise multiple regression analyses were performed to further identify the most significant variables contributing to the variation of WBV. Potential confounders were forced into the model and standardized $\beta$ coefficients were calculated. The explanatory power of the model was expressed as adjusted $\mathrm{R}^{2}$ values. A two-tailed $\mathrm{P}<0.05$ was considered statistically significant. All calculations were performed with SPSS system 15.0 (SPSS Inc., Chicago, IL).

\section{Results}

Of 168 patients, 77 patients (45.8\%) had MS and WBV averaged $5.95 \pm 0.04 \mathrm{cP}$. As previously reported [16, 17], patients had relatively good glycemic, BP and lipid control (Table 1); $53(31.5 \%)$ were treated with diet alone, $85(50.6 \%)$ on oral anti-hyperglycemic drugs and $30(17.9 \%)$ on insulin with or without oral drugs. Anti-hypertensive drugs were given in 87 patients $(51.8 \%)$. Of 75 patients $(44.6 \%)$ on lipid-lowering drugs, 63 and 12 patients were on statins and fibrates, respectively. As patients with anemia (hemoglobin $<13 \mathrm{~g} / \mathrm{dL}$ in men and $<12 \mathrm{~g} / \mathrm{dL}$ in women) and renal failure (eGFR $<45 \mathrm{~mL} /$ $\left.\min / 1.73 \mathrm{~m}^{2}\right)$ were small in number $(\mathrm{n}=15,8.9 \%$ and $\mathrm{n}=6$, $3.6 \%$, respectively), they were not excluded.

Among MS components other than hyperglycemia (all participants had diabetes), elevated BP was the most prevalent (111 patients; 66.1\%; hypertension in 91 patients), followed by abdominal obesity in 63 patients $(37.5 \%)$ and then fasting hypertriglyceridemia (38 patients, $22.6 \%$ ) and low HDL cholesterol (43 patients, 25.6\%).

Diabetes patients with MS had higher WBV and hematocrit as compared to those without MS (Fig. 1). As the number of MS components increased, WBV and hematocrit increased 

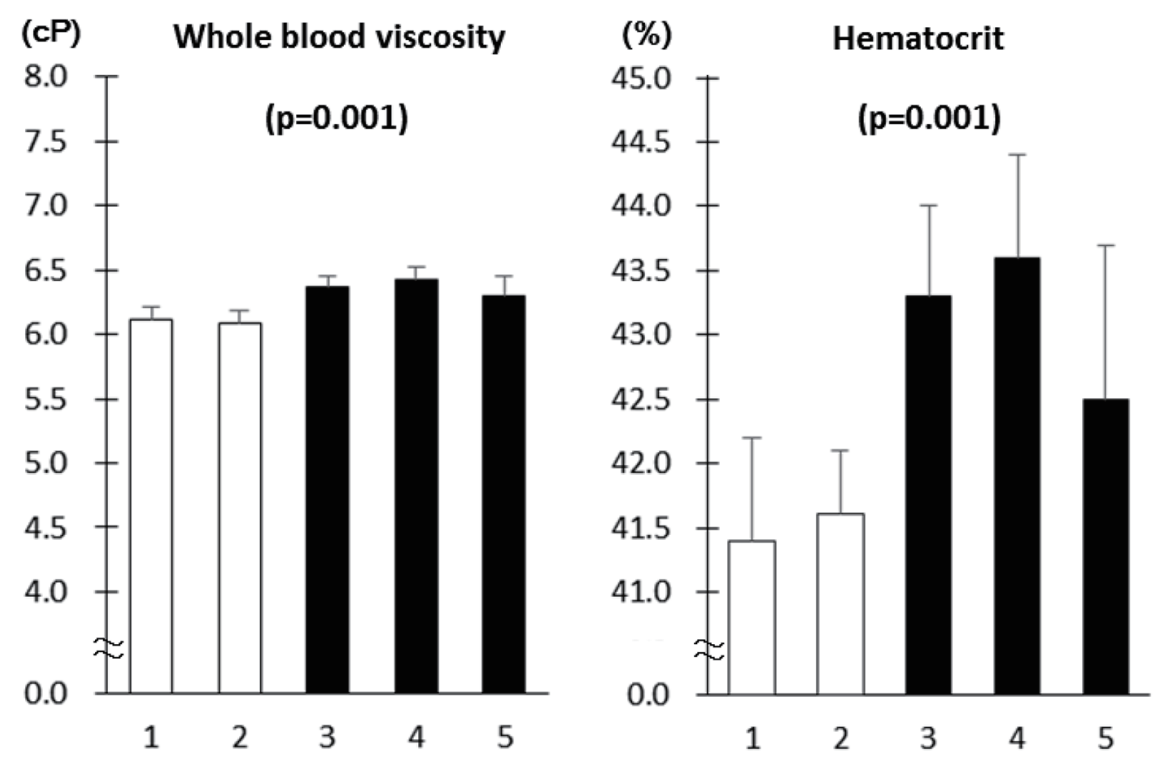

Figure 2. Whole blood viscosity and hematocrit in type 2 diabetes patients in the absence (white columns, $n=91$ ) and presence (black columns, $n=77$ ) of metabolic syndrome (mean $\pm S E$ ).

(Fig. 2). The number of patients with component number from 1 to 5 was $33(19.6 \%), 58(34.5 \%), 42(25.0 \%), 27(16.1 \%)$ and $8(4.8 \%)$, respectively. There was no difference in age, sex, duration of diabetes and therapy for diabetes between patients with and without MS as well as among five component number groups (data not shown). Although the proportion of patients on antihypertensive medications was higher in patients with MS as compared to those without $(68.8 \%$ vs. $37.4 \%, \mathrm{P}<0.001)$, there was no difference in the proportion of patients on diuretics between the two groups $(7.8 \%$ vs. $2.2 \%, \mathrm{P}=0.09$ ).

By univariate analysis (Table 1, simple), WBV was positively associated with male gender and smoking. It was also positively associated with fasting and post-breakfast TG and inversely with HDL cholesterol. In addition, WBV was associated with diastolic BP, uric acid and leukocyte count. Further, serum hepatic enzymes were positively associated with WBV. After controlling for sex (Table 1), associations with diastolic $\mathrm{BP}$, fasting and post-breakfast TG remained significant whereas smoking, liver enzymes, uric acid and leukocyte count were no longer associated with WBV. Those with BMI and waist circumference turned out to be significant after adjusting for sex. There was no association of WBV with glycemia and sys- tolic BP.

We have done multiple regression analysis, which included variables that showed significant associations with WBV in partial correlation analysis as independent variables (Table 2). Male gender, diastolic BP and post-breakfast TG emerged as independent determinants of WBV in type 2 diabetes $\left(\mathrm{R}^{2}=\right.$ $0.258)$.

After controlling for age, sex and smoking, hematocrit correlated positively to BMI $(\mathrm{r}=0.221)$, waist circumference $(\mathrm{r}=0.161)$, fasting and post-breakfast $\mathrm{TG}(\mathrm{r}=0.210$ and 0.200 , respectively) and diastolic $\mathrm{BP}(\mathrm{r}=0.256$, all $\mathrm{P}<0.05$ or less $)$ whereas no association was found with glycemia, HDL cholesterol and systolic BP (data not shown).

\section{Discussion}

The present study has demonstrated that both the presence of MS and the number of MS components were associated with higher WBV and hematocrit in patients with type 2 diabetes. The current study also has demonstrated in type 2 diabetic patients that blood viscosity is associated with post-breakfast TG independent of fasting TG. We confirmed the previous findings

Table 2. Multiple Regression Analysis for Whole Blood Viscosity in Patients With Type 2 Diabetes

\begin{tabular}{llll} 
& Standardized $\boldsymbol{\beta}$ & P values & Cumulative $\mathbf{R}^{2}$ \\
\hline Male sex & 0.406 & 0.000 & 0.183 \\
Diastolic blood pressure & 0.234 & 0.001 & 0.240 \\
Post-breakfast triglyceride & 0.148 & 0.036 & 0.258 \\
\hline
\end{tabular}

Other independent variables included in the model were BMI, waist circumference and fasting triglycerides, all of which showed significant associations with whole blood viscosity after controlling for sex shown in Table 1. 
in non-diabetic subjects that high WBV was associated with all diagnostic criteria for MS except for glycemia [11-13]. It is noted that in the present study MS was diagnosed using intrapersonal means of 12 measurements of waist circumference, BP and HDL cholesterol and those of six measurements of fasting TG during 12 months.

The relationship between WBV and MS has been investigated in non-diabetic population [11-13]; however, there was, as far as we know, no report on this issue in type 2 diabetic patients despite increased WBV in this population [12]. One of the reasons may be that most patients with type 2 diabetes mellitus will have MS [18], specifically in Western countries. For example, MS was found in more than $90 \%$ of type 2 diabetes patients in a UK hospital whose BMI averaged $33 \mathrm{~kg} / \mathrm{m}^{2}$ [22]. Therefore, we evaluated association between the two conditions in Japanese patients with type 2 diabetes, whose BMI averaged $24.2 \mathrm{~kg} / \mathrm{m}^{2}$. To the best of our knowledge, this is the first report on the relationship between WBV and MS in type 2 diabetes although WBV was calculated, not measured. Associations between the number of MS components and measured hemorheological variables including WBV had been reported in some [11, 13, 23] but not in another study [24].

Among MS components, fasting hypertriglyceridemia has been reported to independently predict hemorheological alterations [11]. In the present study, post-breakfast TG was associated with WBV independently of fasting TG in type 2 diabetes patients. It has been reported that insulin resistance directly measured using the hyperinsulinemic glycemic clamp technique, a gold standard for assessing insulin sensitivity, is associated not only with an increase in the large very-lowdensity lipoprotein/chylomicron remnant particles during the postprandial period in type 2 diabetes mellitus [25] but also with an increase in directly measured WBV [26]. Taking these observations into consideration, it may be reasonable to assume that WBV may be associated with insulin resistance even in type 2 diabetes.

Blood viscosity and hematocrit were higher in type 2 diabetes patients with MS as compared to those without in the present study. The Edinburgh Artery Study noted a significant association between blood viscosity or hematocrit and risk for stroke, independently of other risk factors [27]. A crosssectional study reported that high WBV is present not only in subjects with acute brain infarction, but also in those with risk factors for stroke [28]. Several studies with empagliflozin have shown an increase in hematocrit and therefore blood viscosity as secondary effects of this drug [7]. Therefore, physicians need to follow type 2 diabetes patients with MS on SGLT-2 inhibitors closely.

It has been clearly demonstrated that the prevalence of MS is higher in winter than in summer in Japanese male workers in general, in subjects aged greater than or equal to 40 years in particular [29]. This is due to higher serum levels of HDL cholesterol, fasting glucose and systolic and diastolic BP in winter than in summer. In the present study, all variables including HDL cholesterol, and systolic and diastolic BP were repeatedly measured throughout 12 months and hence, seasonal variations in the diagnosis of MS had been avoided. Postprandial TG concentrations were measured after breakfast taken at home in their day-to-day life.
Several limitations deserve mention. We had no direct measurement of blood viscosity and data on other blood components of blood viscosity, such as erythrocyte rigidity and aggregability. Our estimates, however, were based on a prediction equation that has been validated in three prior studies $[20,25,30]$ and WBV is largely determined by hematocrit and plasma protein levels [31]. Antihypertensive treatment has been shown to decrease both WBV and BP, independently of the class of drug [32-35]. In contrast, diuretic therapy tends to increase WBV, at least in the early phase of treatment [36]. Therefore, possible contribution of antihypertensive drug treatment on WBV and other variables cannot be excluded in the present study. Finally, the sample size is small.

\section{Conclusions}

Both the presence of MS and the number of MS components were associated with higher WBV and hematocrit in patients with type 2 diabetes. Physicians need to follow type 2 diabetes patients with MS on SGLT-2 inhibitors closely. Post-breakfast TG is independently predictive of WBV. Postprandial hyperlipidemia may contribute to elevated WBV in type 2 diabetes, and may represent important confounders of the relationship between postprandial hyperlipidemia and atherogenesis in this population.

\section{Acknowledgments}

The authors are indebted to all the participants for their dedicated and conscientious collaboration. We also thank Dr. Takeo Sadamitsu, MS. Ayako Kameyama and Ms. Atsuko Muranaka, Sadamitsu Hospital, for their help.

\section{Conflicts of Interest}

We declare that we have no conflicts of interest.

\section{Author Contributions}

SM, AKT, JU, AYT and MK have made substantial contributions to acquisition, analysis and interpretation of data. KF has been involved in drafting the manuscript. TK has been involved in revising it critically for important intellectual content, have given final approval of the version to be published, and agree to be accountable for all aspects of the work in ensuring that questions related to the accuracy or integrity of any part of the work are appropriately investigated and resolved.

\section{Abbreviations}

ACR: albumin/creatinine ratio; AST: aspartate aminotransferase; ALT: alanine aminotransferase; BP: blood pressure; eGFR: estimated glomerular filtration rate; GGT: gamma-glu- 
tamyltransferase; TG: triglycerides; MS: metabolic syndrome; WBV: whole blood viscosity

\section{References}

1. Nathan DM. Diabetes: Advances in Diagnosis and Treatment. JAMA. 2015;314(10):1052-1062.

2. Gerstein HC, Miller ME, Byington RP, Goff DC, Jr., Bigger JT, Buse JB, Cushman WC, et al. Effects of intensive glucose lowering in type 2 diabetes. N Engl J Med. 2008;358(24):2545-2559.

3. Dormandy JA, Charbonnel B, Eckland DJ, Erdmann E, Massi-Benedetti M, Moules IK, Skene AM, et al. Secondary prevention of macrovascular events in patients with type 2 diabetes in the PROactive Study (PROspective pioglitAzone Clinical Trial In macroVascular Events): a randomised controlled trial. Lancet. 2005;366(9493):12791289.

4. Scirica BM, Bhatt DL, Braunwald E, Steg PG, Davidson J, Hirshberg B, Ohman P, et al. Saxagliptin and cardiovascular outcomes in patients with type 2 diabetes mellitus. N Engl J Med. 2013;369(14):1317-1326.

5. Zinman B, Wanner C, Lachin JM, Fitchett D, Bluhmki E, Hantel S, Mattheus M, et al. Empagliflozin, Cardiovascular Outcomes, and Mortality in Type 2 Diabetes. N Engl J Med. 2015;373(22):2117-2128.

6. Wu JH, Foote C, Blomster J, Toyama T, Perkovic V, Sundstrom J, Neal B. Effects of sodium-glucose cotransporter-2 inhibitors on cardiovascular events, death, and major safety outcomes in adults with type 2 diabetes: a systematic review and meta-analysis. Lancet Diabetes Endocrinol. 2016;4(5):411-419.

7. Imprialos KP, Boutari C, Stavropoulos K, Doumas M, Karagiannis AI. Stroke paradox with SGLT-2 inhibitors: a play of chance or a viscosity-mediated reality? J Neurol Neurosurg Psychiatry. 2016.

8. Stuart J, Kenny MW. Blood rheology. J Clin Pathol. 1980;33(5):417-429.

9. Tamariz LJ, Young JH, Pankow JS, Yeh HC, Schmidt MI, Astor B, Brancati FL. Blood viscosity and hematocrit as risk factors for type 2 diabetes mellitus: the atherosclerosis risk in communities (ARIC) study. Am J Epidemiol. 2008;168(10):1153-1160.

10. Danesh J, Collins R, Peto R, Lowe GD. Haematocrit, viscosity, erythrocyte sedimentation rate: meta-analyses of prospective studies of coronary heart disease. Eur Heart J. 2000;21(7):515-520.

11. Vaya A, Hernandez-Mijares A, Bonet E, Sendra R, Sola E, Perez R, Corella D, et al. Association between hemorheological alterations and metabolic syndrome. Clin Hemorheol Microcirc. 2011;49(1-4):493-503.

12. Gyawali P, Richards RS, Nwose EU, Bwititi PT. Wholeblood viscosity and metabolic syndrome. Clin Lipidol. 2012;7(6):709-719.

13. Irace C, Scavelli F, Carallo C, Serra R, Gnasso A. Plasma and blood viscosity in metabolic syndrome. Nutr Metab Cardiovasc Dis. 2009;19(7):476-480.

14. Ruotolo G, Howard BV. Dyslipidemia of the metabolic syndrome. Curr Cardiol Rep. 2002;4(6):494-500.

15. Heine RJ, Dekker JM. Beyond postprandial hyperglycaemia: metabolic factors associated with cardiovascular disease. Diabetologia. 2002;45(4):461-475.

16. Takenouchi A, Tsuboi A, Terazawa-Watanabe M, Kurata M, Fukuo K, Kazumi T. Direct association of visit-tovisit $\mathrm{HbAlc}$ variation with annual decline in estimated glomerular filtration rate in patients with type 2 diabetes. J Diabetes Metab Disord. 2015;14:69.

17. Kitaoka K, Takenouchi A, Tsuboi A, Fukuo K, Kazumi T. Association of Postbreakfast Triglyceride and Visit-toVisit Annual Variation of Fasting Plasma Glucose with Progression of Diabetic Nephropathy in Patients with Type 2 Diabetes. J Diabetes Res. 2016;2016:4351376.

18. Alberti KG, Eckel RH, Grundy SM, Zimmet PZ, Cleeman JI, Donato KA, Fruchart JC, et al. Harmonizing the metabolic syndrome: a joint interim statement of the International Diabetes Federation Task Force on Epidemiology and Prevention; National Heart, Lung, and Blood Institute; American Heart Association; World Heart Federation; International Atherosclerosis Society; and International Association for the Study of Obesity. Circulation. 2009;120(16):1640-1645.

19. Oka R, Kobayashi J, Yagi K, Tanii H, Miyamoto S, Asano A, Hagishita T, et al. Reassessment of the cutoff values of waist circumference and visceral fat area for identifying Japanese subjects at risk for the metabolic syndrome. Diabetes Res Clin Pract. 2008;79(3):474-481.

20. de Simone G, Devereux RB, Chien S, Alderman MH, Atlas SA, Laragh JH. Relation of blood viscosity to demographic and physiologic variables and to cardiovascular risk factors in apparently normal adults. Circulation. 1990;81(1):107-117.

21. Matsuo S, Imai E, Horio M, Yasuda Y, Tomita K, Nitta $K$, Yamagata $K$, et al. Revised equations for estimated GFR from serum creatinine in Japan. Am J Kidney Dis. 2009;53(6):982-992.

22. Song SH, Hardisty CA. Diagnosing metabolic syndrome in type 2 diabetes: does it matter? QJM. 2008;101(6):487491.

23. Zhang L, Pu K, Zhang SY, Ren WQ. Blood rheological properties are strongly related to the metabolic syndrome in middle-aged Chinese. Int J Cardiol. 2006;112(2):229233.

24. Aloulou I, Varlet-Marie E, Mercier J, Brun JF. Hemorheological disturbances correlate with the lipid profile but not with the NCEP-ATPIII score of the metabolic syndrome. Clin Hemorheol Microcirc. 2006;35(1-2):207-212.

25. Annuzzi G, De Natale C, Iovine C, Patti L, Di Marino $\mathrm{L}$, Coppola S, Del Prato $\mathrm{S}$, et al. Insulin resistance is independently associated with postprandial alterations of triglyceride-rich lipoproteins in type 2 diabetes mellitus. Arterioscler Thromb Vasc Biol. 2004;24(12):23972402.

26. Hoieggen A, Fossum E, Moan A, Enger E, Kjeldsen SE. Whole-blood viscosity and the insulin-resistance syndrome. J Hypertens. 1998;16(2):203-210.

27. Lowe GD, Lee AJ, Rumley A, Price JF, Fowkes FG. Blood viscosity and risk of cardiovascular events: the 
Edinburgh Artery Study. Br J Haematol. 1997;96(1):168173.

28. Coull BM, Beamer N, de Garmo P, Sexton G, Nordt F, Knox R, Seaman GV. Chronic blood hyperviscosity in subjects with acute stroke, transient ischemic attack, and risk factors for stroke. Stroke. 1991;22(2):162-168.

29. Kamezaki F, Sonoda S, Tomotsune Y, Yunaka H, Otsuji Y. Seasonal variation in metabolic syndrome prevalence. Hypertens Res. 2010;33(6):568-572.

30. Moan A, Nordby G, Os I, Birkeland KI, Kjeldsen SE. Relationship between hemorrheologic factors and insulin sensitivity in healthy young men. Metabolism. 1994;43(4):423-427.

31. Letcher RL, Chien S, Pickering TG, Sealey JE, Laragh JH. Direct relationship between blood pressure and blood viscosity in normal and hypertensive subjects. Role of fibrinogen and concentration. Am J Med. 1981;70(6):11951202.

32. Letcher RL, Chien S, Laragh JH. Changes in blood vis- cosity accompanying the response to prazosin in patients with essential hypertension. J Cardiovasc Pharmacol. 1979;1(6 Suppl):S8-20.

33. Chou TZ, Lee KW, Ding YA. Effect of felodipine-ER on blood pressure, platelet function, and rheological properties in hypertension. Can J Cardiol. 1993;9(5):423-427.

34. Shand BI, Gilchrist NL, Nicholls MG, Bailey RR. Effect of losartan on haematology and haemorheology in elderly patients with essential hypertension: a pilot study. J Hum Hypertens. 1995;9(4):233-235.

35. Linde T, Sandhagen B, Hagg A, Morlin C, Danielson BG. Decreased blood viscosity and serum levels of erythropoietin after anti-hypertensive treatment with amlodipine or metoprolol: results of a cross-over study. J Hum Hypertens. 1996;10(3):199-205.

36. Leth A. Changes in plasma and extracellular fluid volumes in patients with essential hypertension during longterm treatment with hydrochlorothiazide. Circulation. 1970;42(3):479-485. 